\title{
Parenteral Treatment of Clinical Mastitis with Tylosin Base or Penethamate Hydriodide in Dairy Cattle
}

\author{
S. McDougall, ${ }^{\star 1}$ K. E. Agnew, † R. Cursons, $\ddagger$ X. X. Hou, $\ddagger$ and C. R. W. Compton* \\ *Animal Health Centre, PO Box 21, Morrinsville, New Zealand \\ †Elanco Animal Health, PO Box 97-046, Manukau City, Auckland, New Zealand \\ fUniversity of Waikato, Hamilton, New Zealand
}

\section{ABSTRACT}

The objective of this study was to compare the clinical and bacteriological cure rates of cows with clinical mastitis following treatment with either tylosin base $(5 \mathrm{~g}$ injected 3 times at 24 -h intervals; $n=306$ ) or penethamate hydriodide (5 g injected 3 times at 24 -h intervals; $\mathrm{n}=289$ ). Duplicate milk samples were collected before treatment and again $14 \pm 3$ and $21 \pm 3 \mathrm{~d}$ later for microbiological analysis. Only those quarters from which gram-positive mastitis pathogens were isolated before treatment were included in the analyses. Streptococcus uberis was the most prevalent isolate. The number of cows with clinical failure (i.e., retreated within $21 \mathrm{~d}$ of enrollment) did not differ between treatments (64 vs. 63 , respectively). At the quarter level, there was no difference in the proportion of bacteriological cure between treatments ( 81.2 vs. $83.8 \%$ for penethamate hydriodide or tylosin, respectively). The proportions of clinical and bacteriological cure were influenced by age, herd, severity of mastitis, number of glands within the cow with clinical mastitis, bacterial species, and days postpartum at enrollment. There was no difference between treatment groups for SCC (4.46 vs. $4.44 \pm 0.08$, mean \pm standard error of the difference in ln SCC for cows treated with penethamate hydriodide or tylosin, respectively) or production of milk solids (1.45 vs. $1.48 \pm 0.02 \mathrm{~kg} / \mathrm{d}$ of milk fat + protein, for the penethamate hydriodide or tylosin treatment, respectively). Overall, there was no difference in the proportions of clinical failure (17.3 vs. $16.5 \%$ of cows treated with penethamate hydriodide or tylosin, respectively) or bacteriological cure $(79.8$ vs. $82.0 \%$ of cows treated with penethamate hydriodide or tylosin, respectively), or in SCC or milk production between dairy cows with clinical mastitis and those treated for clinical mastitis with 1 of 2 parenteral antibiotic therapies.

Key words: mastitis, antibiotic, bacteriology, therapy

Received April 20, 2006.

Accepted October 5, 2006.

${ }^{1}$ Corresponding author: smcdoug@ahc.co.nz

\section{INTRODUCTION}

Clinical mastitis incurs significant costs to the herd owner related to the costs of diagnosis, treatment (drug costs, milk discard), ongoing production losses from damaged quarters, increased probability of cow death, and increased risk of antibiotic residues in milk. In New Zealand, the cumulative incidence of clinical mastitis is approximately 15 cases $/ 100$ cows per lactation, with $85 \%$ of cases being detected in the first month following calving. Gram-positive pathogens, particularly Streptococcus uberis, are the most prevalent pathogens isolated from clinical mastitis cases in early lactation in New Zealand (McDougall, 1998, 2003). For example, $92.0 \%$ of 578 quarters with clinical mastitis from which a pathogen was isolated were associated with grampositive pathogens, whereas only $4.7 \%$ were coliforms (McDougall, 1998). This is in contrast to studies undertaken in cattle that were predominantly housed, where Escherichia coli is often the most prevalent environmental mastitis pathogen (Erskine et al., 1988; Schukken et al., 1989). Consequently, clinical mastitis therapy in New Zealand is focused on treatment of grampositive pathogens.

Treatment of clinical mastitis commonly involves antibiotics and supportive therapy, such as fluids and nonsteroidal antiinflammatory medications. The proportions of bacteriological cure following antibiotic treatment of clinical mastitis are between 37 and 67\% (Faull and Ward, 1975; Jarp et al., 1989; Roberson et al., 2004). Parenteral therapy may have clinical advantages over intramammary infusion, such as when multiple quarters within a cow are infected, when swelling of the mammary quarter is present and diffusion of antibiotics delivered by an intramammary route may be compromised, or when animal behavior increases the risk to operators trying to infuse antibiotics. A number of parenteral antibiotics are licensed for mastitis therapy in New Zealand, including tylosin base and penethamate hydriodide. Both these compounds are weak bases and are lipophilic, which results in higher concentrations in milk than in plasma. Hence, they are more likely than less lipophilic compounds to achieve concentra- 
tions greater than the MIC (Ziv, 1980). Tylosin is a member of the macrolide antibiotic family and acts by inhibiting RNA-dependent protein synthesis by blocking translation at the ribosome. Macrolides have generally low MIC for gram-positive cocci (both Staphylococcus and Streptococcus spp.) and moderate MIC for Enterococcus spp., but high MIC for gram-negative bacteria (Salmon et al., 1998). Likewise, penethamate, as a benzyl penicillin prodrug, has moderate to low MIC for gram-positive cocci. A number of studies have evaluated penethamate for the treatment of clinical (McDougall, 1998; Sérieys et al., 2005) and subclinical (St. Rose et al., 2003) mastitis; however, no peer-reviewed studies have apparently evaluated tylosin as a clinical mastitis treatment. Therefore, the objective of this bioequivalency study was to compare the proportions of clinical and bacteriological cure for these 2 parenteral antibiotics with label claims for mastitis therapy. The null hypothesis being tested was that there would be a difference in response to treatment between the 2 antibiotics.

\section{MATERIALS AND METHODS}

Cows were enrolled from 30 pasture-fed, spring-calving dairy herds. The herd size was $347 \pm 134$ (mean \pm SD). Herd owners presented 1,070 cases of clinical mastitis in cows that calved between the start and 57 $\pm 2.1 \mathrm{~d}$ after the start of the seasonal calving period. The herd owners diagnosed mastitis on the basis of grossly visible changes to milk (e.g., presence of clots or flecks, blood or discoloration of the milk) or changes in the mammary quarter, such as swelling and pain. Cows were excluded if they had been treated with any antibiotic in the $30 \mathrm{~d}$ preceding enrollment or had not calved at presentation.

Within $4 \mathrm{~h}$ of notification by the herd owner, a technician assessed each cow for the presence of changes in milk composition [e.g., presence of clots (coded as nil, minor, or major), blood (yes/no), discoloration of the milk (yes/no), or swelling of the mammary quarter(s) (yes/no)] and recorded the BCS on a 1 to 10 scale (Roche et al., 2004). A California Mastitis Test (CMT) was performed on all quarters and the result was recorded on a 0 , trace, 1,2 , or 3 scale. Following aseptic preparation of the teat end and discard of the first 3 streams of milk, duplicate milk samples (about $5 \mathrm{~mL}$ ) were collected from each quarter defined as having clinical mastitis. Cows were assigned to treatment within herd by randomizing sequential pairs of presented cows to 1 of 2 treatments (d 0$)$. Treatments were either 3 i.m. injections of $5 \mathrm{~g}$ of penethamate hydriodide (Mamyzin; Boehringer Ingelheim, Ingelheim, Germany) or 3 i.m. injections of $5 \mathrm{~g}$ of tylosin base (Tylan 200; Elanco Animal Health, Auckland, New Zealand) at 24-h intervals between treatments. Initial treatment was undertaken by the technician, with the remaining treatments left on-farm for the herd owner to administer. Milk was discarded for $72 \mathrm{~h}$ after the final treatment. Duplicate milk samples (about $5 \mathrm{~mL}$ ) were collected from each enrolled quarter again at $14 \pm 3 \mathrm{~d}$ and $21 \pm 3 \mathrm{~d}$ postenrollment by the technicians at twice-weekly visits to each herd.

Herd owners assessed the treated quarters at each milking. Where the herd owner determined that the clinical condition of the quarter was not improving (i.e., presence of clots or flecks, blood, or discoloration of the milk persisting beyond the end of the treatment period), they had the option of altering the treatment to another active treatment or route of treatment, or both. This was recorded and the cow was defined as a "clinical treatment failure" where retreatment occurred $<22 \mathrm{~d}$ after initial diagnosis and enrollment. Where additional treatments were given before $\mathrm{d} 14$ or $\mathrm{d} 21$, the routine posttreatment milk samples were not collected.

All herds participated in milk production recording (herd testing) 2 to 5 times ( $\mathrm{n}=30$ herds undertook 2 tests, 29 herds undertook 3 tests, 26 herds undertook 4 tests, and 1 herd undertook 5 tests) during the lactation at approximately 2 -mo intervals (i.e., $58 \pm 12,70$ \pm 12 , and $64 \pm 12 \mathrm{~d}$, respectively, between tests 1 and 2 , tests 2 and 3 , and tests 3 and 4). The test date, milk yield (as milk solids/cow day, i.e., $\mathrm{kg}$ of milk fat $+\mathrm{kg}$ of milk protein), and SCC data were retrieved from a database (Livestock Improvement Corporation, Hamilton, New Zealand) for analysis.

All disease data were recovered from herd records following completion of the study to determine whether any enrolled cows had been treated with other antibiotics in the $30 \mathrm{~d}$ preceding enrollment or within $21 \mathrm{~d}$ after enrollment. The study was undertaken with the approval of the Animal Ethics Committee of AgResearch Ruakura (Hamilton, New Zealand).

\section{Bacterial Culture}

Milk samples were kept at $4^{\circ} \mathrm{C}$ and submitted for culture within $12 \mathrm{~h}$ of collection. Following mixing by inversion, milk $(10 \mu \mathrm{L})$ was spread onto a quarter of a $0.1 \%$ esculin, $5 \%$ sheep blood agar plate (Fort Richard, Auckland, New Zealand) and incubated for $48 \mathrm{~h}$ at $37^{\circ} \mathrm{C}$. The culture and identification basically followed the procedures of the National Mastitis Council of the United States (Harmon et al., 1990). Modifications to this protocol were inclusion of $0.1 \%$ esculin in the primary culture plates and use of the staphyloslide test (Becton Dickinson, Franklin Lakes, NJ) rather than a tube coagulase reaction to differentiate coagulasepositive from coagulase-negative staphylococci. Gram- 
Table 1. Fate of cows diagnosed with clinical mastitis in $\geq 1$ quarter by herd owners and presented for clinical treatment with penethamate hydriodide or tylosin base

\begin{tabular}{|c|c|c|c|c|}
\hline \multirow[b]{2}{*}{ Treatment } & \multicolumn{2}{|c|}{$\begin{array}{l}\text { Penethamate } \\
\text { hydriodide }\end{array}$} & \multicolumn{2}{|c|}{ Tylosin } \\
\hline & $\mathrm{n}$ & $\%$ & $\mathrm{n}$ & $\%$ \\
\hline Cows presented & 530 & & 540 & \\
\hline Presented before calving or missing calving date & 6 & 1.1 & 4 & 0.7 \\
\hline No clinical signs detected by technician & 3 & 0.6 & 1 & 0.2 \\
\hline \multicolumn{5}{|l|}{ Bacteriology result } \\
\hline "No growth" & 86 & 16.2 & 94 & 17.4 \\
\hline Other bacterial species & 66 & 12.5 & 60 & 11.1 \\
\hline Gram-positive cocci & 369 & 69.6 & 381 & 70.6 \\
\hline \multicolumn{5}{|l|}{ Fate of gram-positive cows } \\
\hline Clinical failure $^{1}$ & 64 & 17.3 & 63 & 16.5 \\
\hline Antibiotic treatment for other reasons ${ }^{1}$ & 4 & 1.1 & 2 & 0.5 \\
\hline Failure to represent for sampling & 5 & 1.4 & 3 & 0.8 \\
\hline Sampled wrong time ${ }^{2}$ & 7 & 1.9 & 7 & 1.8 \\
\hline Final cows presented & 289 & 54.5 & 306 & 56.7 \\
\hline
\end{tabular}

${ }^{1}$ Herd owner diagnosed the failure to respond to therapy or diagnosis of clinical mastitis within an enrolled quarter within $21 \mathrm{~d}$ of initial enrollment. Note that where treatment with other antibiotics for another condition or for clinical failure and treatment occurred, all quarters within a cow were excluded from further analysis because of the potential for antibiotic diffusion between quarters, and hence false-negative bacteriological results.

${ }^{2}$ That is, the first posttreatment sampling occurred $<11$ and $>17 \mathrm{~d}$ after the initial enrollment, or the second posttreatment sampling occurred $>11 \mathrm{~d}$ after the first posttreatment sampling.

positive cocci were tested with the catalase test. Catalase-positive isolates were assumed to be Staphylococci, coagulase-positive isolates were defined as Staphylococcus aureus, and coagulase-negative isolates were defined as CNS. Gram-positive, catalase-negative cocci were further evaluated with the Christie-AtkinsMunch-Petersen (CAMP) test. Gram-positive, catalase-negative, esculin-positive, and CAMP-variable isolates were defined as Strep. uberis, whereas esculinnegative, CAMP-positive isolates were defined as Streptococcus agalactiae, and esculin-negative, CAMP-negative isolates were defined as Streptococcus dysgalactiae.

\section{Genotyping of Isolates}

Confirmation of the microbiological identity of selected isolates (Strep. uberis, $\mathrm{n}=103$; Staph. aureus, $\mathrm{n}=77$ ) was achieved by using PCR of the $16 \mathrm{~S}$ to $23 \mathrm{~S}$ rRNA intergenic spacer region (Forsman et al., 1997). These isolates were selected from the enrollment $(\mathrm{d} 0)$ samples and had been inoculated onto Dorset egg slopes (Fort Richard, Auckland, New Zealand) and held at $4^{\circ} \mathrm{C}$ before DNA extraction.

Genomic DNA of Strep. uberis and Staph. aureus was isolated from an overnight culture of bacteria grown on

Table 2. Effect of treatment, number of quarters infected with gram-positive cocci, and the highest clot score within each cow on the risk of a cow being defined as a clinical failure by a herd owner

\begin{tabular}{|c|c|c|c|c|c|c|c|}
\hline \multirow[b]{2}{*}{ Item } & \multicolumn{3}{|c|}{ Clinical failure } & \multirow[b]{2}{*}{$\mathrm{RR}^{1}$} & \multicolumn{2}{|c|}{$95 \% \mathrm{CI}$} & \multirow[b]{2}{*}{$P$} \\
\hline & No & Yes & Total & & Low & High & \\
\hline \multicolumn{8}{|l|}{ Treatment $^{2}$} \\
\hline Penethamate hydriodide & 306 & 64 & 370 & & & & \\
\hline Tylosin & 319 & 63 & 382 & 1.00 & 0.70 & 1.39 & 0.988 \\
\hline \multicolumn{8}{|l|}{ Clots at enrollment ${ }^{3}$} \\
\hline No clots & 77 & 6 & 83 & & & & \\
\hline Minor & 371 & 54 & 425 & 1.81 & 0.77 & 3.82 & 0.168 \\
\hline Major & 177 & 67 & 244 & 4.37 & 2.11 & 7.51 & 0.001 \\
\hline \multicolumn{8}{|c|}{ Quarters positive for gram-positive ${ }^{4}$} \\
\hline 1 & 564 & 104 & 668 & & & & \\
\hline $2+$ & 61 & 23 & 84 & 2.01 & 1.29 & 2.90 & 0.003 \\
\hline
\end{tabular}




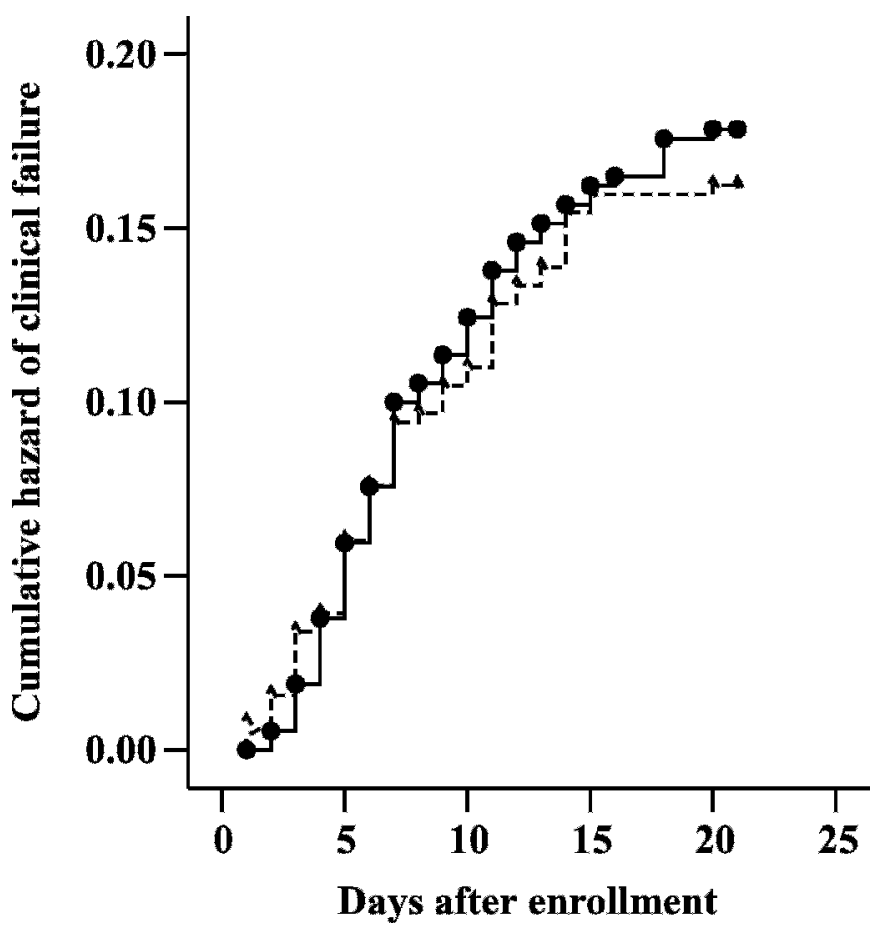

Figure 1. Cumulative hazard of clinical failure by time (d) after enrollment for cows with clinical mastitis treated with either penethamate hydriodide (solid line, 0 ) or tylosin (dashed line, $\triangle$ ).

$5 \%$ sheep blood agar. Colonies were suspended in 100 $\mu \mathrm{L}$ of lysozyme solution $(50 \mathrm{mg} / \mathrm{mL})$ and incubated at $37^{\circ} \mathrm{C}$ for $15 \mathrm{~min}$. Then $300 \mu \mathrm{L}$ of lysis solution $(0.05 \mathrm{M}$ EDTA; $0.1 M$ Tris, pH 9; $0.1 M$ NaCl; $1.0 \%$ SDS) was added. The mixture was incubated at $65^{\circ} \mathrm{C}$ for $30 \mathrm{~min}$. This was followed by addition of $300 \mu \mathrm{L}$ of $5 \mathrm{M} \mathrm{LiCl}$ and $750 \mu \mathrm{L}$ of chloroform, and the solution was rotated for $5 \mathrm{~min}$. The phases were separated by centrifugation at $13,000 \times g$ for $10 \mathrm{~min}$. The aqueous phase was collected and nucleic acids were precipitated by addition of an equivalent volume of isopropanol. The DNA was pelleted at $13,000 \times g$ for $15 \mathrm{~min}$, washed with $1.0 \mathrm{~mL}$ of $70 \%$ ethanol, resuspended in $100 \mu \mathrm{L}$ of $10 \mathrm{~m} M$ Tris, $\mathrm{pH}$ 8.0; $1 \mathrm{~m} M$ EDTA (TE buffer), and stored at $4^{\circ} \mathrm{C}$. Genomic DNA extracted from bacterial isolates was further identified by PCR of the $16 \mathrm{~S}$ to $23 \mathrm{~S}$ rRNA spacer region. The primers used were 5'-TAA GGA ACA CGT TGG TTA AG-3' and 5'-TCC AGT CCT TAG ACC TTC T-3' for Strep. uberis, and 5'-TCT TCA GAA GAT GCG GAA TA-3' and 5'-TAA GTC AAA CGT TAA CAT ACG$3^{\prime}$ for Staph. aureus (Forsman et al., 1997). The PCR conditions were 1) $94^{\circ} \mathrm{C}, 2 \mathrm{~min}$; 2) $55^{\circ} \mathrm{C}, 20 \mathrm{~s}$; 3) $68^{\circ} \mathrm{C}$, $35 \mathrm{~s}$; 4) $94^{\circ} \mathrm{C}, 20 \mathrm{~s}$; 5) $55^{\circ} \mathrm{C}, 20 \mathrm{~s}$; 6$) 68^{\circ} \mathrm{C}, 40 \mathrm{~s}$; 7) with steps 4 to 6 repeated for 40 cycles. Amplification products were analyzed on $1.5 \%$ (wt/vol) agarose gel, and Strep. uberis and Staph. aureus were confirmed by the presence of a 340- and a 420-bp band, respectively
(Forsman et al., 1997). A 100-bp ladder (Invitrogen Australia Ltd., Mount Waverley, Victoria, Australia) and a negative control lane were included on all gels.

\section{Definitions for Bacteriological Results}

Samples were defined as contaminated where $\geq 3$ bacterial species were identified. Where one of the duplicate samples was not contaminated, the result from the uncontaminated sample was used for analysis. Where both samples were contaminated and the sample was from $\mathrm{d} 0$, the quarter was excluded from the study. Where the contaminated sample was obtained on $\mathrm{d} 14$ or 21 , duplicate samples were collected again within 3 $\mathrm{d}$ for culture. Quarters were defined as infected and remained enrolled after d 0 when $>2$ cfu of Staph. aureus, CNS, Strep. agalactiae, Strep. dysgalactiae, or Strep. uberis was isolated.

A quarter was defined as having undergone a bacteriological cure when each of the d 14 and d 21 samples was culture-negative for the bacterial species present at enrollment, or when different bacterial species from those isolated on $\mathrm{d} 0$ were the only isolates. When 2 bacterial species were isolated at $\mathrm{d} 0$, a cure was defined as having occurred when neither of the species was present in any of the $d 14$ or 21 samples.

\section{Sample Size Calculations}

From previous studies, the proportion rate of bacteriological cure was expected to be approximately $70 \%$ (McDougall, 1998). To demonstrate with 95\% confidence and $80 \%$ power (i.e., $\alpha=0.05, \beta=0.2$ ) that the 2 treatments had a proportion of cure within $10 \%$ of each other, we calculated that a minimum of 313 quarters per group (2-sided test) were required (Martin et al., 1987; Schukken and Deluyker, 1995).

\section{Statistical Analysis}

Cows from which gram-positive cocci were isolated from at least one gland were included in the analysis for the clinical failure and assessment of treatment group balance. Cows were removed from analysis for the bacteriological cure 1) if they were not represented for resampling, 2) if they were represented outside the defined time periods (i.e., 11 to $17 \mathrm{~d}$ and 18 to $24 \mathrm{~d}$ for resampling 1 and 2 , respectively), 3 ) if they were treated with antibiotics before the final resampling, or 4) when a gram-positive pathogen was not isolated either from one quarter within the cow (for the cow-level analysis) or from the quarter (for the quarter-level analysis).

All data were examined for outlying values by plotting the continuous variables, tabulating categorical 
Table 3. Number and relative risk $(R R)$ of bacteriological cure at the cow level for cows with $\geq 1$ quarter diagnosed with clinical mastitis and treated with either penethamate hydriodide or tylosin base

\begin{tabular}{|c|c|c|c|c|c|c|c|}
\hline \multirow[b]{2}{*}{ Item } & \multicolumn{3}{|c|}{ Bacteriological cure } & \multirow[b]{2}{*}{$\mathrm{RR}$} & \multicolumn{2}{|c|}{$95 \% \mathrm{CI}$} & \multirow[b]{2}{*}{$P$} \\
\hline & No & Yes & Total & & Low & High & \\
\hline \multicolumn{8}{|l|}{ Treatment $^{1}$} \\
\hline Penethamate hydriodide & 60 & 229 & 289 & & & & \\
\hline Tylosin & 55 & 251 & 306 & 1.15 & 0.79 & 1.58 & 0.455 \\
\hline \multicolumn{8}{|l|}{ Blood in milk ${ }^{2}$} \\
\hline No & 94 & 435 & 529 & & & & \\
\hline Yes & 21 & 45 & 66 & 0.27 & 0.13 & 0.53 & 0.001 \\
\hline \multicolumn{8}{|c|}{ Staphylococcus aureus isolated ${ }^{3}$} \\
\hline No & 80 & 468 & 548 & & & & \\
\hline Yes & 35 & 12 & 47 & 0.06 & 0.03 & 0.14 & 0.001 \\
\hline \multicolumn{8}{|l|}{ Calving to treatment, ${ }^{4} \mathrm{~d}$} \\
\hline$\leq 1$ & 40 & 204 & 244 & & & & 0.017 \\
\hline 2 & 17 & 83 & 100 & 0.77 & 0.39 & 1.43 & 0.436 \\
\hline 3 to 6 & 22 & 115 & 137 & 0.69 & 0.36 & 1.24 & 0.222 \\
\hline $7+$ & 36 & 78 & 114 & 0.35 & 0.17 & 0.68 & 0.002 \\
\hline \multicolumn{8}{|l|}{ Age $^{5}$} \\
\hline 2 & 30 & 193 & 223 & & & & 0.001 \\
\hline 3 to 4 & 20 & 104 & 124 & 0.92 & 0.47 & 1.69 & 0.805 \\
\hline 5 to 6 & 21 & 84 & 105 & 1.06 & 0.52 & 1.99 & 0.864 \\
\hline $7+$ & 44 & 99 & 143 & 0.32 & 0.17 & 0.60 & 0.001 \\
\hline \multicolumn{8}{|c|}{ Quarters positive for gram-positive ${ }^{6}$} \\
\hline 1 & 98 & 438 & 536 & & & & \\
\hline $2+$ & 17 & 42 & 59 & 0.47 & 0.24 & 0.89 & 0.019 \\
\hline
\end{tabular}

${ }^{1}$ Reference category $=$ penethamate treatment.

${ }^{2}$ Presence of blood in the milk of $\geq 1$ quarter; reference category = no blood detected.

${ }^{3}$ Staphylococcus aureus isolated from $\geq 1$ quarter; reference category = no Staph. aureus isolated from any quarter.

${ }^{4}$ Interval from calving to first treatment of clinical mastitis (d); reference category $=\leq 1 \mathrm{~d}$ after calving.

${ }^{5}$ Age in years; reference category $=2$ yr of age.

${ }^{6}$ Number of quarters within a cow from which gram-positive cocci were isolated; reference category = 1 .

variables, and undertaking descriptive statistics. The balance of treatment groups by age, DIM at enrollment, and breed was assessed using univariate techniques, specifically, one-way ANOVA for age and DIM at enrollment, and a $\chi^{2}$ test for breed (coded as Jersey or Friesian when the animal was $>3 / 4$ of that breed, otherwise coded as crossbred). The main outcomes of interest were the proportion of clinical failure, the proportion of bacteriological cure, the natural log (ln) of SCC, and milk production.

The cow was the unit of interest for the failure of clinical treatment, the proportion of bacteriological cure at the cow level (i.e., all quarters within the cow cured), SCC, and milk production. The proportion of cure was also analyzed at the quarter level. Logistic regression was used for dichotomous outcome variables (i.e., loss to followup or bacteriological cure rate), whereas a GLM was used to analyze the SCC and milk production data.

The main independent (explanatory) variable was treatment. However, because age, DIM, and herd were shown to affect the bacteriological cure rate following antibiotic therapy (Sol et al., 2000), these variables were initially included in the modeling process as fixed effects. Additionally, the relationship between the clinical signs present at enrollment and clinical failure and bacteriological cure were of interest, and were initially examined for association during the model-building process. The calving date of each cow relative to the planned start of calving for the herd was used in the model-building process.

Associations between the independent and dependent variables were initially examined by univariate methods ( $\chi^{2}$ for categorical variables and ANOVA for continuous variables) for the proportion of bacteriological cure at the quarter and cow levels and clinical failure at the cow level. Associated variables $(P<0.2)$ were subjected to backward and forward stepwise logistic regression procedures. First-order interactions between treatment and all independent variables remaining in each model following the stepwise logistic regression were tested and removed when $P>0.1$. The model goodness of fit was examined using the Hosmer and Lemeshow test (Hosmer and Lemeshow, 2000), and the number of outliers was counted to ensure that $<5 \%$ of all cases were outliers. Because more than one quarter within a cow could be enrolled and because cows 
Table 4. Outcome for quarters presented with clinical mastitis and treated with either penethamate hydriodide or tylosin base

\begin{tabular}{|c|c|c|c|c|}
\hline \multirow[b]{2}{*}{ Item } & \multicolumn{2}{|c|}{ Penethamate hydriodide } & \multicolumn{2}{|c|}{ Tylosin } \\
\hline & $\mathrm{n}$ & $\%$ & $\mathrm{n}$ & $\%$ \\
\hline Quarters presented & 654 & & 688 & \\
\hline Presented before calving & 3 & 0.5 & 1 & 0.1 \\
\hline No clinical signs & 1 & 0.2 & 0 & 0.0 \\
\hline \multicolumn{5}{|l|}{ Bacteriology result } \\
\hline "No growth" & 184 & 28.1 & 192 & 27.9 \\
\hline Other bacterial species & 40 & 6.1 & 39 & 5.7 \\
\hline Gram-positive cocci & 423 & 64.7 & 432 & 62.8 \\
\hline \multicolumn{5}{|l|}{ Fate of gram-positive quarters } \\
\hline Clinical failure ${ }^{1}$ & 75 & 17.7 & 83 & 19.2 \\
\hline Antibiotic treatment for other reasons ${ }^{1}$ & 5 & 1.2 & 2 & 0.5 \\
\hline Failure to represent for sampling & 6 & 1.5 & 3 & 0.7 \\
\hline Sampled wrong time ${ }^{2}$ & 10 & 2.4 & 9 & 2.1 \\
\hline Quarters enrolled & 327 & & 335 & \\
\hline
\end{tabular}

${ }^{1}$ Herd owner diagnosed failure to respond to therapy, or diagnosis of clinical mastitis within an enrolled quarter within $21 \mathrm{~d}$ of initial enrollment. Note that where treatment with other antibiotics for another condition or for clinical failure and treatment occurred, all quarters within a cow were excluded from further analysis because of the potential for antibiotic diffusion between quarters, and hence false negative bacteriological results.

${ }^{2}$ That is, the first posttreatment sampling occurred $<11$ and $>17 \mathrm{~d}$ after initial enrollment, or the second posttreatment sampling occurred $>11 \mathrm{~d}$ after the first posttreatment sampling.

were nested within herds in the study, the potential existed for the clustering of data (Barkema et al., 1997; Dohoo et al., 2003). The degree of clustering of the variance inflation factor was calculated (Dohoo et al., 2003), and the deviance was divided by degrees of freedom from the logistic regression models examined. The deviance/degrees of freedom was 0.78 for the proportion of bacteriological cure model at the quarter level, indicating underdispersion rather than overdispersion. Hence, for the proportion of cure analysis, logistic regression without correction for clustering was used for the analysis. The use of odds ratios may result in overestimation of the effect size where the outcome is not rare, so odds ratios were converted to relative risks using the methodology of Zhang and Kai (1998).

The time from enrollment to clinical failure (days) was examined using the Kaplan-Meier survival analysis, with treatment as the main effect. The 2 treatment groups were compared using the log-rank test.

The SCC was natural $\log (\ln )$ transformed to normalize the data. Milk production data were analyzed as milk solids, that is, the sum of milk fat $(\mathrm{kg} / \mathrm{d})$ and milk protein $(\mathrm{kg} / \mathrm{d})$ per cow. Only cows from which a grampositive pathogen was isolated at enrollment and that were not clinical failures were included in these analyses. A small number of cows that herd owners had failed to present for resampling or that were re-presented at the wrong time were included in this analysis. The numbers of cows included in the final analyses were 276 and 280 for penethamate and tylosin, respectively, for the SCC analysis and 276 and 276 for penethamate and tylosin, respectively, for the milk solids analysis. Data from the first 3 production recordings for the lactation were used for analysis. The production data for each cow were listed in date order and were coded by the production recording event number within the lactation (production recording test 1 , production recording test 2 , and production recording test 3 ). The DIM were calculated for each test. The data from one herd, which undertook only 2 production recordings across the lactation, was not included in the SCC and milk production models. Initially, a univariate analysis was undertaken using one-way ANOVA for categorical predictors and linear regression for continuous predictors. Associated factors $(P<0.2)$ were used in a forward manual modelbuilding approach using a repeated-measures GLM. Initially, treatment and herd (fixed effects) and DIM as a covariate were included in the models because of the design and known confounding. Next, factors associated $(P<0.2)$ with $\ln$ SCC were manually added to the model and a reduction of the Bayesian information criteria was used to determine whether the model fit improved with the addition of each variable. Because cows were clustered within herd, the potential for clustering and its effects of underestimating variance were examined. The intraclass correlation $(\rho)$ for $\ln$ SCC was 0.02 , indicating a low degree of clustering. Nonetheless, because of the number of cows within each herd (mean = 17), the variance inflation factor was calculated as 1.34 , indicating a potential to underestimate variance and hence, overestimate the significance of main effects. Because herds were not randomly selected and because 
fitting herd as a random effect did not improve the model fit or produce any significant changes in estimates of coefficients or standard errors of the main effect, herd was modeled as a fixed effect. Data are reported as estimated marginal means from the final model. The assumption that the variance-covariance matrix is circular was not met (Mauchly's test, $P<0.05$ ); thus, the conservative, lower-bound adjustment to the degrees of freedom of the $F$-test was used for testing the within-subjects effects. Data were stored in an Access database (Microsoft Corp., Redmond, WA) and data analysis was undertaken using SPSS (v. 13; SPSS Inc., Chicago, IL) or SAS (v. 9.0; SAS Institute Inc., Cary, $\mathrm{NC})$.

\section{RESULTS}

\section{Cow-Level Analysis}

There were no differences in age between the treatment groups $[4.6 \pm 0.1$ vs. $4.4 \pm 0.1$ yr old (mean \pm SEM) for the penethamate- and tylosin-treated animals, respectively; $P=0.11$, DIM at diagnosis $(5.7 \pm 0.4$ vs. $5.1 \pm 0.4 \mathrm{~d}$ for the penethamate- and tylosin-treated animals, respectively, $P=0.28$ ), or breed distribution (50.5, 24.8, and $24.8 \%$ vs. $51.7,23.7$, and $24.6 \%$ for Friesians, crossbreds, and Jerseys for the penethamateand tylosin-treated animals, respectively; $P=0.90$ ). The proportion of cows that were clinical failures was not different between treatments $(P=0.99$; Tables 1 and 2 ) and was increased with the presence of major clots in milk at enrollment $(P<0.001$; Table 2$)$, with more than one gland within the cow from which gram-positive cocci were isolated $(P=0.003$; Table 2$)$, and with the number of DIM at diagnosis $(P=0.001)$. The hazard of clinical failure did not vary between treatment groups (Figure 1; $P=0.83$, log-rank test).

At the univariate level, the proportion of cow-level cure was associated with herd $(P=0.10)$, age code $(P$ $<0.01)$, swelling of one or more quarters $(P=0.18)$, detection of blood in the milk $(P<0.01)$, whether grampositive cocci were isolated from $>1$ quarter $(P=0.05)$, isolation of Staph. aureus $(P<0.01)$, isolation of Strep. uberis $(P<0.01)$, and the interval from calving to diagnosis $(P<0.01)$. In the final model, the proportion of cows with a bacteriological cure did not differ between treatment groups (79.2 vs. $82.0 \%$ for penethamate and tylosin, respectively; $P=0.46$; Table 3 ). The proportion of cure was decreased in cows that had blood in the milk at enrollment $(P<0.01$; Table 3$)$, where Staph. aureus was isolated from $\geq 1$ quarter $(P<0.001$; Table 3 ), where diagnosis occurred $\geq 7 \mathrm{~d}$ after calving $(P=$ 0.002; Table 3 ), in cows $\geq 7$ yr old $(P<0.001$; Table 3$)$, and in cows in which gram-positive cocci were isolated in $>1$ quarter $(P=0.02$; Table 3$)$. There were no interac-
A
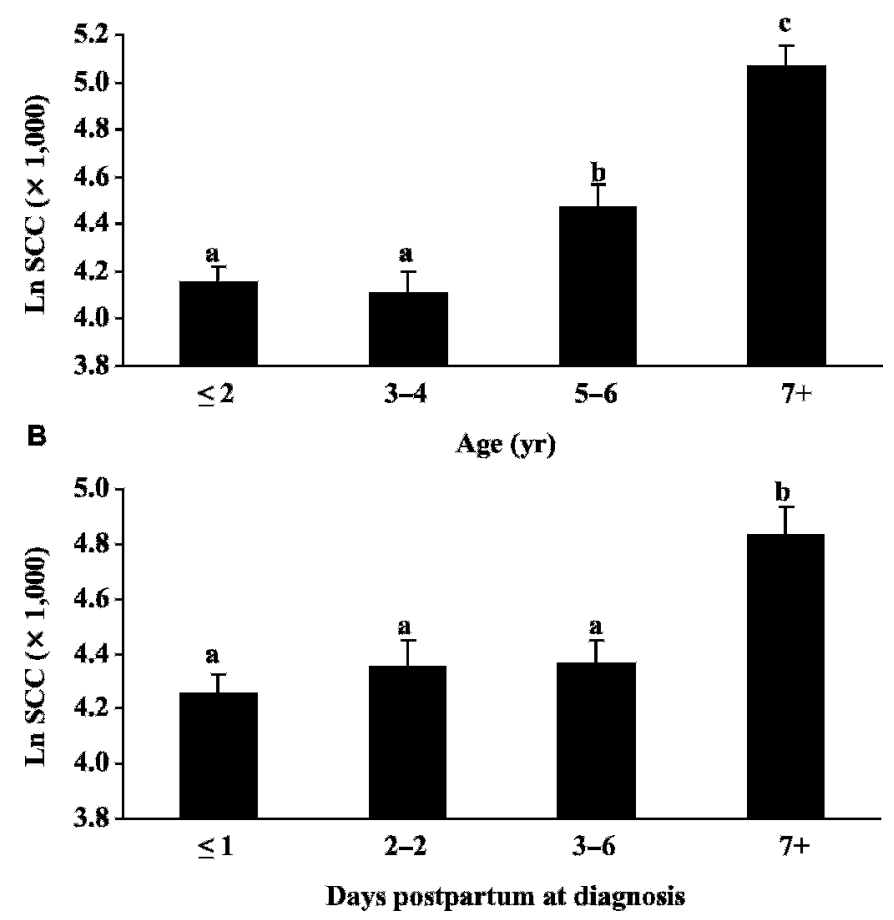

Figure 2. Estimated marginal mean (SEM) of the natural $\log (\ln )$ of SCC at the first 3 posttreatment production recordings by (A) age in years and (B) day postpartum at the diagnosis of clinical mastitis. Columns with different letters differ $(P<0.05)$.

tions between treatment and any other of the main effects (all $P>0.2$ ).

The ln SCC was not different between treatments (4.46 vs. $4.44 \pm 0.08$; mean $\pm \mathrm{SE}$ of the difference of $\ln$ SCC at herd tests 1 to 3 for cows treated with penethamate vs. tylosin, respectively; $P=0.79$ ). Overall, the $\ln$ SCC differed among herds $(P<0.01)$, increased with age $(P<0.01$; Figure $2 \mathrm{~A})$, and was higher for cows first diagnosed with clinical mastitis $\geq 7 \mathrm{~d}$ after calving, compared with those diagnosed on or before $6 \mathrm{~d}$ after calving $(P<0.01$; Figure 2B).

Milk solids production was not different among treatments (1.45 vs. $1.48 \pm 0.02$, mean $\pm \mathrm{SE}$ of the difference, $\mathrm{kg}$ of milk solids/d at production recordings 1 to 3 for cows treated with penethamate vs. tylosin, respectively; $P=0.09)$. Overall, the production of milk solids declined with the herd test number $(P<0.001)$, increased with age $(P<0.01)$, differed among herds $(P<0.001)$, and varied among breeds $(P<0.01)$.

There was no difference in the proportion of all cows initially treated that were subsequently removed from the herds for clinical or subclinical mastitis during or at the end of lactation [5/289 (1.7\%) vs. 8/306 (2.6\%) for cows treated with penethamate and tylosin, respectively; $P>0.2$. 
Table 5. Proportion of bacteriological cure (number and percentage) for quarters diagnosed with clinical mastitis and treated with either penethamate hydriodide or tylosin base

\begin{tabular}{|c|c|c|c|c|c|c|c|c|c|}
\hline \multirow[b]{2}{*}{ Item } & \multicolumn{3}{|c|}{ Penethamate hydriodide } & \multicolumn{3}{|c|}{ Tylosin } & \multicolumn{3}{|c|}{ Total } \\
\hline & Enrolled, $\mathrm{n}$ & Cured, $\mathrm{n}$ & $\%$ & Enrolled, $\mathrm{n}$ & Cured, n & $\%$ & Enrolled, $\mathrm{n}$ & Cured, $\mathrm{n}$ & $\%$ \\
\hline Streptococcus uberis & 253 & 222 & 87.7 & 235 & 211 & 89.8 & 488 & 433 & 88.7 \\
\hline Staphylococcus aureus & 18 & 6 & 33.3 & 22 & 7 & 31.8 & 40 & 13 & 32.5 \\
\hline CNS & 29 & 22 & 75.9 & 42 & 38 & 90.5 & 71 & 60 & 84.5 \\
\hline Combined $^{1}$ & 8 & 3 & 37.5 & 20 & 13 & 65 & 28 & 16 & 57.1 \\
\hline Total & 325 & 264 & 81.2 & 334 & 280 & 83.8 & 659 & 544 & 82.5 \\
\hline
\end{tabular}

${ }^{1}$ That is, 2 pathogens isolated [Staph. aureus and Streptococcus spp. ( $\mathrm{n}=13$ total); Staph. aureus and CNS ( $\mathrm{n}=3$ total); or Streptococcus spp and CNS ( $=12$ total)].

\section{Quarter-Level Analysis}

The distribution of number of quarters with clinical mastitis within cows was $82.2 \%$ with 1 quarter, $13.1 \%$ with 2 quarters, $2.4 \%$ with 3 quarters, and $2.2 \%$ with 4 quarters enrolled. The CMT scores at enrollment did not differ between treatments $(3.3,9.1$, and $87.6 \%$ vs. $3.5,6.2$, and $90.3 \%$ for CMT scores of 0 to 1,2 , or 3 for penethamate- and tylosin-treated quarters, respectively; $P>0.2$ ). There were no differences between treatment groups $(P>0.2)$ in the number of quarters excluded from final analysis (Table 4).

Streptococcus uberis was the most common isolate (Table 5). The identities of all of the 103 Strep. uberis and 77 Staph. aureus isolates subjected to PCR were confirmed (Figure 3). The proportion of quarters from which Staph. aureus was isolated increased with age $(3.6,4.4,10.2$, and $8.8 \%$ of quarters from cows 2,3 to 4,5 to 6 , and $\geq 7 \mathrm{yr}$ old, respectively) and with day after calving at enrollment $(5.7,4.5,4.4,5.3,6.2,6.0$, and $17.7 \%$ of quarters with clinical mastitis cultured Staph. aureus when enrolled $0,1,2,3,4$ to 5,6 to 13 , and $>13$ d; $P<0.05)$.

There was no difference in the proportion of bacteriological cure between treatments [264/325 (81.2\%) vs. 280/334 (83.8\%) for penethamate- and tylosin-treated quarters, respectively; Tables 5 and $6 ; P=0.2$ ]. The proportion of cure was lower in cows $\geq 7 \mathrm{yr}$ of age $(P<$ 0.01 ; Table 6 ). The proportion of cure was lower for quarters from which Staph. aureus, Strep. dysgalactiae, or multiple bacterial species were isolated relative to quarters from which Strep. uberis was isolated (Table 6). The proportion of cure was lower for quarters within cows that had swelling of the mammary gland (Table 6). There were no first-order interactions between treatment and any of the other main effects in the model (all $P>0.2$ ).

\section{DISCUSSION}

This study examined the response to therapy for clinical mastitis following treatment with 2 parenteral anti- biotic treatments: tylosin and penethamate. There was no difference between treatments in cows lost to followup, the proportion of clinical failure, the time from enrollment to clinical failure, the proportion of bacteriological cure at either the quarter or cow level, or in SCC and milk production. Thus, the null hypothesis that the treatments were different was rejected, and the alternate hypothesis that the treatments did not differ was accepted.
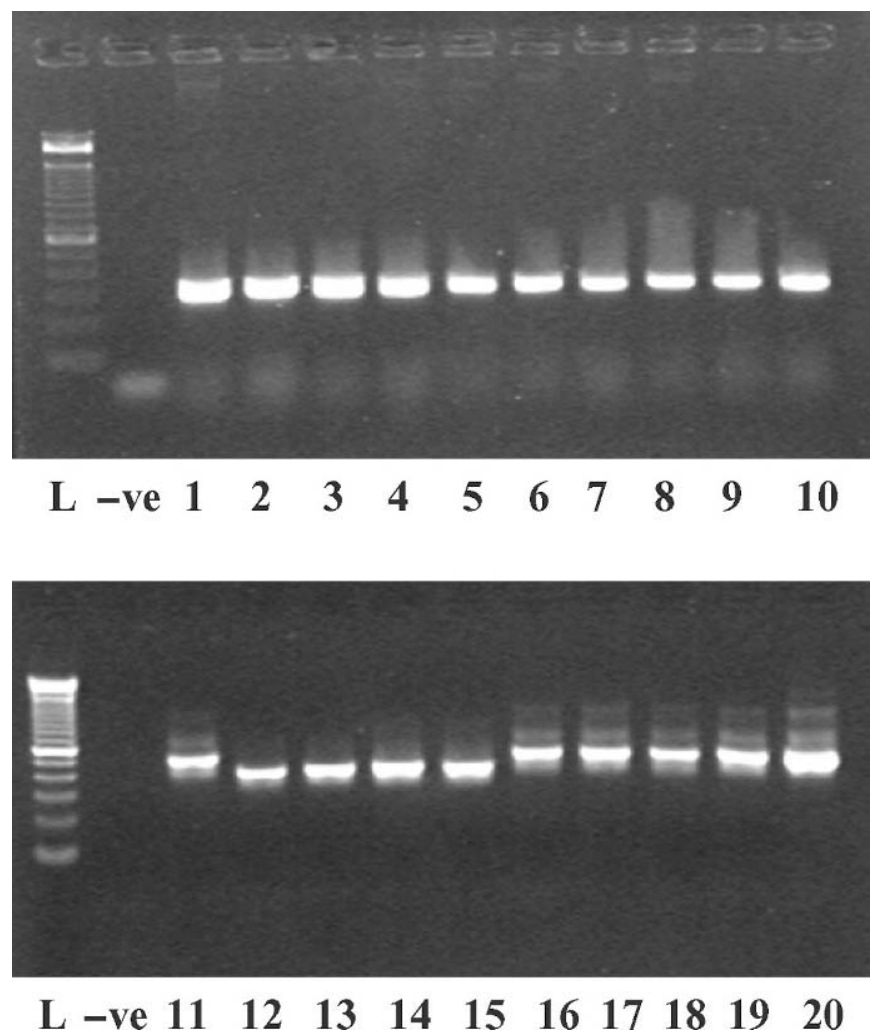

Figure 3. The PCR products of Streptococcus uberis (upper panel) and Staphylococcus aureus (lower panel) isolates following amplification with species-specific primers (Forsman et al., 1997). "L" indicates the 100-bp ladder lane, "-ve" indicates the negative control lane, and the numbers 1 to 20 indicate samples. 
Table 6. Factors affecting the proportion of bacteriological cure at the quarter level of clinical mastitis cases treated with either penethamate hydriodide or tylosin base

\begin{tabular}{|c|c|c|c|c|c|c|c|}
\hline \multirow[b]{2}{*}{ Item } & \multicolumn{3}{|c|}{ Bacteriological cure } & \multirow[b]{2}{*}{$\mathrm{RR}^{1}$} & \multicolumn{2}{|c|}{$95 \% \mathrm{CI}$} & \multirow[b]{2}{*}{$P$} \\
\hline & No & Yes & Total & & Low & High & \\
\hline \multicolumn{8}{|l|}{ Treatment $^{2}$} \\
\hline Penethamate hydriodide & 61 & 264 & 325 & & & & \\
\hline Tylosin & 54 & 280 & 334 & 1.05 & 0.97 & 1.11 & 0.20 \\
\hline \multicolumn{8}{|l|}{$\mathrm{Age}^{3}$} \\
\hline 2 & 29 & 219 & 248 & & & & 0.01 \\
\hline 3 to 4 & 19 & 116 & 135 & 0.94 & 0.79 & 1.03 & 0.23 \\
\hline 5 to 6 & 22 & 96 & 118 & 0.93 & 0.77 & 1.03 & 0.19 \\
\hline $7+$ & 45 & 113 & 158 & 0.72 & 0.54 & 0.87 & 0.01 \\
\hline \multicolumn{8}{|l|}{ Bacteria $^{4}$} \\
\hline Streptococcus uberis & 55 & 433 & 488 & & & & \\
\hline Streptococcus dysgalactiae & 10 & 22 & 32 & 0.81 & 0.57 & 0.98 & 0.02 \\
\hline Staphylococcus aureus & 27 & 13 & 40 & 0.36 & 0.19 & 0.58 & 0.01 \\
\hline CNS & 11 & 60 & 71 & 0.89 & 0.71 & 1.01 & 0.08 \\
\hline Multiple & 12 & 16 & 28 & 0.58 & 0.33 & 0.83 & 0.01 \\
\hline \multicolumn{8}{|l|}{ Swelling of gland ${ }^{5}$} \\
\hline No & 33 & 198 & 231 & & & & \\
\hline Yes & 82 & 345 & 427 & 0.92 & 0.91 & 0.80 & 0.02 \\
\hline
\end{tabular}

A priori, the sample size required to declare bioequivalency was 313 quarters per treatment group (Martin et al., 1987; Schukken and Deluyker, 1995) with $95 \%$ confidence and $80 \%$ power $(\alpha=0.05, \beta=0.2)$ with a $<10 \%$ difference in the proportion of cure between the treatment and control products. Sufficient quarters $(\mathrm{n}=$ 659 ) were present for the final analysis to test the hypothesis. The effect of clustering can result in the nonindependence of observations, and where this is not adjusted for, can result in underestimation of variance and hence, overestimation of the significance of the results (Barkema et al., 1997; Dohoo et al., 2003). However, the calculated intraclass correlations from the current study were small $(\rho<0.1)$ and the effect of the intraclass correlations would not have altered the inferences of the study. Inclusion of herd as a random effect did not improve the model fit; consequently, the simpler fixed model results were reported.

A number of potential biases may have been present because of the design of the current study. Herd owners were responsible for the presentation of cows, for excluding cows deemed to have systemic disease, and for deciding which cows were clinical failures and hence, required retreatment. There was likely variation among herds in how inclusion and exclusion rules were applied. Still, this is unlikely to have altered the inferences where the criteria were applied uniformly across treatment groups. There were no differences in age, DIM at diagnosis, or breed between treatment groups, and the treatments were balanced within herds. Additionally, herd owners were unaware of which cows were to be allocated to which treatment until the technicians had enrolled a specific case. Consequently, herd owners would have been unable to bias allocation to treatment groups. After enrollment, herd owners were aware of which treatment each cow had been assigned to and potentially could have biased the outcomes by defining more of one treatment group than another as clinical failures. Still, there was no difference between treatments in the proportion of clinical failures, suggesting that such selection did not occur. Herd owners were not directed in the criteria on which to define clinical failure and hence, on which to retreat cows. This was a deliberate decision because the inferences that we wished to draw were related to current on-farm management practices in New Zealand. By imposing criteria around retreatment decisions, the external validity of the study would have been reduced. Thus, although there would have been variation among herds in the criteria for retreatment, as long as these criteria were applied equally among the treatment groups, the inferences drawn from the study were sound.

Clinical failure, that is, retreatment of an animal within $21 \mathrm{~d}$ of enrollment because of perceived failure of treatment to return the milk and quarter to normal, occurred in approximately $12 \%$ of all cows and in $17 \%$ of cows from which a gram-positive pathogen was isolated from $\geq 1$ quarter. There was no difference between treat- 
ments in the proportions of clinical failure. Increasing the severity of clinical signs at enrollment, as indicated by the presence of more obvious clots in the milk, resulted in a higher probability of clinical failure. In the univariate analysis, the presence of swelling of the mammary quarters, discoloration of the milk, and the presence of gross clots in the milk were all associated with an increased risk of clinical failure. Because of the colinearity of these clinical signs, only the clot variable remained in the final model. Similarly, only the number of quarters from which a gram-positive pathogen was isolated remained in the model, although the presence of Strep. uberis, Staph. aureus, and any gram-positive pathogen was associated with an increased risk of clinical failure in the univariate analysis. The risk of clinical failure increased with the interval from calving to diagnosis. This may be related to an increased prevalence of Staph. aureus isolation with time postpartum at diagnosis and hence, an inferior overall bacteriological cure. Later diagnosis postpartum may be associated with more chronic infections and a longer interval between acquiring an infection and treatment. Early diagnosis and treatment were associated with increased proportions of clinical and bacteriological cure (Milner et al., 1997; Hillerton and Semmens, 1999). The pseudo- $\mathrm{R}^{2}$ for the final model was 0.30 , indicating that $30 \%$ of the variation for clinical failure was described by the model. Thus, the final model was only moderately predictive. On the other hand, herd owners may be able to use clinical signs and the time postpartum at enrollment to indicate the probability of clinical treatment success. Where the risk of clinical and bacteriological cure failure is high, prolonged therapy may result in higher proportions of cure (Hillerton and Kleim, 2002; Oliver et al., 2004).

The bacteriological cure rate of approximately $80 \%$ at the cow level and $83 \%$ at the individual quarter level in the present study is high compared with previous European and North American studies (Faull and Ward, 1975; Jarp et al., 1989; Guterbock et al., 1993), but is similar to a number of studies in New Zealand's pasture-based production systems (McDougall, 1998; McDougall, 2003). The difference may be related to the relatively low prevalence of Staph. aureus (7.9\% of cows and $11.9 \%$ of enrolled quarters) and the high prevalence of Strep. uberis in the current study compared with other studies. The proportion of cure for Staph. aureus is lower than that for Strep. uberis, as shown in the current study as well as in others (Pearson and Mackie, 1979; Barkema et al., 2006). The low proportion of cure for Staph. aureus is related to a combination of host, bacterial, and therapy factors (Barkema et al., 2006). The present study demonstrated that infections treated early in lactation had higher proportions of bacteriologi- cal cure than those detected and treated later in lactation. This is contrary to other studies, which found similar cure rates irrespective of the time postpartum at which diagnosis and treatment occurred (Sol et al., 2000). This may be related to cows that are treated later in lactation having had a longer duration of infection before detection and treatment. In an intervention study, a shorter interval from acquisition of a new infection to treatment was associated with a higher proportion of clinical and bacteriological cure (Milner et al., 1997). It may be that infections detected and treated later in lactation are more severe than those early in lactation, because the sensitivity to detection of clinical mastitis by milking staff may decline once cows have moved from the colostrum group into the main milking herd.

In conclusion, there was no difference between the 2 parenteral treatments for clinical mastitis in terms of the loss to followup, proportion of clinical failure, time from enrollment to clinical failure, proportion of bacteriological cure at either the quarter or cow level or in the SCC or milk production, or final removal rate from the herds for mastitis. The response to treatment was modified by herd, age of the cow, cow breed, DIM at treatment initiation, and bacterial species associated with clinical mastitis. Moreover, none of these potential confounders interacted with the treatment type, indicating that the treatments were likely to produce similar responses over a range of clinical situations.

\section{ACKNOWLEDGMENTS}

The technical assistance of Fiona Anniss, Kathryn Berry, Elizabeth Blythe, Rhonda Cooper, Judith Forno, Mike Kingstone, and Shelley Roberts is gratefully acknowledged. The involvement and patience of the herd owners is gratefully acknowledged. This study was funded by Elanco Animal Health.

\section{REFERENCES}

Barkema, H. W., Y. H. Schukken, T. J. G. M. Lam, D. T. Galligan, M. L. Beiboer, and A. Brand. 1997. Estimation of interdependence among quarters of the bovine udder with subclinical mastitis and implications for analysis. J. Dairy Sci. 80:1592-1599.

Barkema, H. W., Y. H. Schukken, and R. N. Zadoks. 2006. Invited review: The role of cow, pathogen, and treatment regimen in the therapeutic success of bovine Staphylococcus aureus mastitis. J. Dairy Sci. 89:1877-1895.

Dohoo, I. R., S. W. Martin, and H. Stryhn. 2003. Veterinary Epidemiologic Research. AVC Inc., Charlottetown, Prince Edward Island, Canada.

Erskine, R. J., R. J. Eberhart, L. J. Hutchinson, S. B. Spencer, and M. A. Campbell. 1988. Incidence and types of clinical mastitis in dairy herds with high and low somatic cell count. J. Am. Vet. Med. Assoc. 192:761-762.

Faull, W. B., and W. R. Ward. 1975. Treatment of clinical mastitis: Two intramammary formulations compared. Vet. Rec. 96:127129. 
Forsman, P., A. Tilsalatimisjarvi, and T. Alatossava. 1997. Identification of staphylococcal and streptococcal causes of bovine mastitis using 16S-23S ribosomal-RNA spacer regions. Microbiology 143:3491-3500.

Guterbock, W. M., A. L. van Eenennaam, R. J. Anderson, I. A. Gardner, J. S. Cullor, and C. A. Holmberg. 1993. Efficacy of intramammary antibiotic therapy for treatment of clinical mastitis caused by environmental pathogens. J. Dairy Sci. 76:3437-3444.

Harmon, R. J., R. J. Eberhart, D. E. Jasper, B. E. Langlois, and R. A. Wilson. 1990. Microbiological Procedures for the Diagnosis of Bovine Udder Infection. 3rd ed. National Mastitis Council Inc., Arlington, VA.

Hillerton, J. E., and K. E. Kleim. 2002. Effective treatment of Streptococcus uberis clinical mastitis to minimize the use of antibiotics. J. Dairy Sci. 85:1009-1016.

Hillerton, J. E., and J. E. Semmens. 1999. Comparison of treatment of mastitis by oxytocin or antibiotics following detection according to changes in milk electrical conductivity prior to visible signs. J. Dairy Sci. 82:93-98.

Hosmer, D. W., and S. Lemeshow. 2000. Applied Logistic Regression, 2nd ed. John Wiley and Sons, New York, NY.

Jarp, J., H. P. Bugge, and S. Larsen. 1989. Clinical trial of three therapeutic regimens for bovine mastitis. Vet. Rec. 124:603-634.

Martin, S. W., A. H. Meek, and P. Willeberg. 1987. Veterinary Epidemiology: Principles and Methods. Iowa State University Press, Ames.

McDougall, S. 1998. Efficacy of two antibiotic treatments in curing clinical and subclinical mastitis in lactating dairy cows. N. Z. Vet. J. 46:226-232.

McDougall, S. 2003. Intramammary treatment of clinical mastitis of dairy cows with a combination of lincomycin and neomycin, or penicillin and dihydrostreptomycin. N. Z. Vet. J. 51:111-116.

Milner, P., K. L. Page, and J. E. Hillerton. 1997. The effects of early antibiotic-treatment following diagnosis of mastitis detected by a change in the electrical-conductivity of milk. J. Dairy Sci. 80:859-863.

Oliver, S. P., B. E. Gillespie, S. J. Headrick, H. Moorehead, P. Lunn, H. H. Dowlen, D. L. Johnson, K. C. Lamar, S. T. Chester, and W. M. Moseley. 2004. Efficacy of extended ceftiofur intramammary therapy for treatment of subclinical mastitis in lactating dairy cows. J. Dairy Sci. 87:2393-2400.

Pearson, J. K. L., and D. P. Mackie. 1979. Factors associated with the occurrence, cause and outcome of clinical mastitis in cattle. Vet. Rec. 105:456-463.

Roberson, J. R., L. D. Warnick, and G. Moore. 2004. Mild to moderate clinical mastitis: Efficacy of intramammary amoxicillin, frequent milk-out, a combined intramammary amoxicillin, and frequent milk-out treatment versus no treatment. J. Dairy Sci. 87:583-592.

Roche, J. R., P. G. Dillon, C. R. Stockdale, L. H. Baumgard, and M. J. VanBaale. 2004. Relationships among international body condition scoring systems. J. Dairy Sci. 87:3076-3079.

Salmon, S. A., J. L. Watts, F. M. Aarestrup, J. W. Pankey, and R. J. Yancey, Jr. 1998. Minimum inhibitory concentrations for selected antimicrobial agents against organisms isolated from the mammary glands of dairy heifers in New Zealand and Denmark. J. Dairy Sci. 81:570-578.

Schukken, Y. H., and H. A. Deluyker. 1995. Design of field trials for the evaluation of antibacterial products for therapy of bovine clinical mastitis. J. Vet. Pharmcol. Ther. 18:274-283.

Schukken, Y. H., F. J. Grommers, D. van de Geer, and A. Brand. 1989. Incidence of clinical mastitis on farms with low somatic cell counts in bulk milk. Vet. Rec. 125:60-64.

Sérieys, F., Y. Raguet, L. Goby, H. Schmidt, and G. Friton. 2005. Comparative efficacy of local and systemic antibiotic treatment in lactating cows with clinical mastitis. J. Dairy Sci. 88:93-99.

Sol, S., O. C. Sampimon, H. W. Barkema, and Y. H. Schukken. 2000 Factors associated with cure after therapy of clinical mastitis caused by Staphylococcus aureus. J. Dairy Sci. 83:278-284.

St. Rose, S. G., J. M. Swinkels, W. D. J. Kremer, C. L. J. J. Kruitwagen, and R. N. Zadoks. 2003. Effect of penethamate hydriodide treatment on bacteriological cure, somatic cell count and milk production of cows and quarters with chronic subclinical Streptococcus uberis or Streptococcus dysgalactiae infection. J. Dairy Res. 70:387-394.

Zhang, J., and F. Y. Kai. 1998. What's the relative risk? A method of correcting the odds ratio in cohort studies of common outcomes. J. Am. Med. Assoc. 280:1690-1691.

Ziv, G. 1980. Practical pharmacokinetic aspects of mastitis therapy 2. Practical and therapeutic applications. Vet. Med. (Praha) 75:469-474. 